\title{
Konfrontation und Provokation als einzige Option?
}

Spielen Sie gerne? Natürlich nicht, Spiele sind für Kinder - wir sind ja erwachsen, sind Verantwortungsträger, sind ernsthaft ...

Erinnern Sie sich noch an Ihr letztes Spiel? Spielten Sie «Eile mit Weile», haben Sie sich gefreut, wenn Sie Ihren Partner blockieren, verzögern oder «nach Hause stellen» konnten - vielleicht haben Sie diese Aktionen mit einem entsprechenden Kommentar begleitet und damit Öl ins Feuer gegossen, den Ärger verstärkt?

Erinnern Sie sich noch, wie Sie sich gefühlt haben, wenn es Ihnen so ergangen ist - haben Sie das nächste Spiel dazu genutzt, dem Partner eines auszuwischen, oder haben Sie sich geweigert, mit ihm ein neues Spiel zu wagen?

Natürlich gibt es eine Vielzahl von Spielen, bei denen wir andere Erfahrungen machen können, wo wir lernen, dass sich Kooperation lohnt, dass Anerkennung der Leistung eines Partners die Akzeptanz steigert, Allianzen und damit das Weiterkommen fördert, Lust weckt, Dinge auszuprobieren, neue Erfahrungen zu machen.

Natürlich haben unser Praxisalltag und unsere Arbeit zur Umgestaltung des Gesundheitswesens nichts Spielerisches...
Mit dem vertragskonformen Abschluss der Kostenneutralität im ambulanten Bereich haben wir als Ärztinnen und Ärzte bewiesen, dass wir unser Engagement zur Kostenkontrolle ernst nehmen. Mit der LeiKoV bestärken wir diese Absicht und wollen diese Arbeit fortsetzen. Wir sind bereit, diese Aktivitäten auch auf den UV/MV/IV-Bereich auszudehnen.

Wie geht es Ihnen, wenn Sie nun lesen, dass die Versicherer diese Verträge nicht antreten wollen und der zuständige Bundesrat Forderungen stellt, ohne vorher Abklärungen oder Absprachen mit den Beteiligten zu treffen? Dass Zugeständnisse der Versicherer an einzelne Facharztgruppen von einem Tag auf den andern ausgesetzt oder zumindest in Frage gestellt werden?

Manchmal wünsche ich mir, dass Versicherer, Gesundheitspolitiker und selbstverständlich auch wir Ärztinnen und Ärzte mehr spielen würden aber eben: nicht nur «Eile mit Weile» ...

Dr. med. Olivier Kappeler, Mitglied des Zentralvorstandes der FMH 